\title{
REGIME DE CONSTITUIÇÃO DE OBJETOS E DESCONSTRUÇÃO DA RELAÇÃO DE OBJETO*
}

Ernildo Stein**

SÍNTESE - Na tradição filosófica a questão do objeto tem levado a discussões de importância no âmbito da análise do conhecimento. $\mathrm{Na}$ psicanálise a expressăo relação de objeto herdou as dificuldades que o problema do objeto suscitava na filosofia. $O$ ensaio pretende sugerir um novo tratamento para a questão através do uso de alguns elementos da analítica existencial. É assim que irá tratar do modo de ser-no-mundo e a perturbação da relação de objeto, partindo da questäo da finitude do Dasein para realizar uma espécie de desconstrução hermenêutica dessa relação. Um exame específico da questão do objeto perdido irá revelar novas faces da questão na relação de ambigüidade entre culpa e melancolia diante dos objetos da experiência de um tipo de obra de arte contemporânea.

PALAVRAS-CHAVE - relação de objeto, desconstrução, finitude, culpa e melancolia.
ABSTRACT - In the philosophycal tradition, the topic of the object has lead to major discussions in the field of knowledge analysis. In Psychoanalisis, the expression object relationship has inherited the same difficulties. This essay aims at suggesting a new approach to the subject making use of some elements of existential analytics. Departing from the Dasein finitude topic to perform an hermeneutic desconstruction of such relationship, this essay will be dealing under the same approach with the way of being-in-world and the disorder of the object relationship. A specific investigation of the lost object topic will reveal new aspects of the problem in its ambiguity relationship between guilt and melancholia before objects of experience of the kind of contemporary works of art.

KEY WORDS - Object relationship, desconstruction, finitude, guilt, melancholia.

\section{1 - 0 modo de ser-no-mundo e a perturbação na relação de objeto}

Pretendo explorar, em três etapas, o conceito de mundo em Heidegger e sua articulação com o conceito de objeto e a relação de objeto na psicanálise

* Os assuntos analisados neste ensaio foram expostos num ciclo de conferências intitulado Filosofia e Psicanálise na UnB nos dias 3 a 5 de novembro de 1997.

** Professor do Curso de Pós-Graduação em Filosofia da PUCRS.

\begin{tabular}{|l|l|l|l|l|l|}
\hline VERITAS & Porto Alegre & v. 43 & $n^{\circ} 1$ & Março 1998 & p. 109-133 \\
\hline
\end{tabular}


A primeira parte consistirá numa análise sumária da aproximação entre 0 conceito de mundo em Heidegger e a perturbação na relação de objeto na psicanálise. Vou tomar como ponto de partida um dos modos fundamentais do Dasein o lidar com os entes disponíveis. Tomarei, por outro lado, a relação de objeto como um conceito simplesmente dado.

Neste exame, no entanto, já se firmará uma posição clara com a compreensão do que pode ser determinado e do que determina, no encontro entre mundo e relação de objeto.

Ao tirar as conseqüências de como, no lidar com os entes disponiveis, pode resultar uma perturbação na relação de objeto, isto é, através de um plus inesperado que surge na forma da angústia diante da totalidade e se mostra como o estranho, o sinistro, o inobjetivável, irá mostrar-se a necessidade da desconstrução do conceito relação de objeto a partir da análise da finitude do Dasein.

A tendência para o encobrimento da existência como totalidade (impossivel), como finitude, reside em absolutizar o estar-junto-do-ente, no seu puro caráter de presente, procura silenciar o ser-adiante-de-si-mesmo, do cuidado como futuro e $o$ já-ser-em da faticidade. O Dasein posto diante de si mesmo como totalidade finita, perderia a possibilidade do ser-junto-dos-entes objetivados, como objetos acabados e plenos. Mostrar-se-ia a transitoriedade e a incompletude do lidar com os entes disponiveis no presente e, desse mesmo lidar, apareceria o modo como 0 ente coagulado como objeto aparece sem fundo e se perde no nada, isto é, aponta para o objeto perdido irrecuperável na finitude e contudo, tendo que ser sustentado como tal, na angústia. Aquilo de que propriamente fugia era do caráter de insuportabilidade de um objeto ausente.

A partir dessa estrutura construída desde um modo de ser do Dasein se irá impor a necessidade da desconstrução da relação de objeto.

A análise dessa segunda parte nos permitirá preparar uma hipótese sobre a relação entre culpa e melancolia, na perspectiva de um novo regime de objetos. Esta terceira parte terá como finalidade mostrar, usando um exemplo, como é produtiva a substituição da relação de objeto, pela de objeto perdido, no contexto da teoria da falta, usando o exemplo de um tipo de experiência diante da arte contemporânea.

\section{II}

Depois de Heidegger ter atingido pela analítica provisória da cotidianeidade 0 ser do estar-aí: o cuidado, o filósofo desenvolveu, na segunda seção, a questão da temporalidade. Ela é denominada o sentido do ser do estar-aí. "Sentido" significa aqui algo como o lugar da compreensão, espaço onde se realiza o articular-se do cuidado, horizonte onde os existenciais do estar-aí recebem sua determinação. Mas a própria temporalidade faz parte do estar-aí. É pela modificação de sua temporalidade que os modos fundamentais do estar-ai se distinguem em:

representar - 0 ente puramente existente

lidar - com o ente disponivel

compreender-se - em vista da existência. 
Para o desenvolvimento do meu trabalho irei analisar basicamente uma modificação da temporalidade e do cuidado, o lidar com o ente disponível.

Lidando com o martelo, o estar-aí torna presente o martelo num ser-para-que (Um-zu), enquanto a partir do em-vista-de (Um Willen) de sua existência conta com um por-que (Wozu) e, desta maneira, segura o martelo no com-que (Womit) de sua serventia.

\section{$U m$ - Zu - ser-para-que}

Wozu - aquilo-por-que

Womit - com-que

são os esquemas dos êxtases de futuro, presente, passado nos quais o estar-aí expressa sua temporalidade praticamente como intratemporalidade. "A diferença entre 0 existir e o lidar com o ente disponivel resulta, portanto, da modificação da temporalidade do estar-aí, que, de um lado, acentua a historicidade e, de outro, a intratemporalidade."

Os três modos de ser do estar-aí, são modos de ser da temporalidade (Zeitlichkeit) e ao mesmo tempo sua manifestação ou dispersão só pode dar-se a partir de uma outra temporalidade (Temporalität) como espaço de distinção de todos os modos possiveis de ser.

Examinarei, aqui, apenas uma modificação da temporalidade e espero que a partir dela se possa mostrar que não é a perturbação da relação de objeto que revela uma perturbação do ser-no-mundo, mas que também não é possivel pensar uma perturbação do ser-no-mundo que iria interferir na relação de objeto. Apresentarei um aspecto daquela que me parece ser a verdadeira solução e apenas a partir do lidar com o ente disponivel.

É no presentificar na forma do ser-junto-dos-entes, na forma do lidar com os entes disponíveis, que se dá a origem do objeto enquanto elemento que preenche o conhecimento e acalma, pelo sentido de posse, a busca da vontade.

Mas, em Ser e tempo, essa dimensão do presente leva o ser humano a encobrir as dimensões de futuro e passado, fugindo este, assim, de uma totalidade (finita) na qual está inserido e que o constitui como ser-no-mundo.

É o cuidado como ser do estar-aí, portanto, como estrutura ontológica, que se articula na tríplice dimensão de futuro, passado e presente - existência, faticidade e decaída - como totalidade sempre implicada em cada um dos modos fundamentais do ser-aí, que são modificações da temporalidade.

\section{III}

Podemos abordar a questão central a partir da constatação de que o lidar com o ente disponivel faz parte do todo da existência humana. A existência mesma é a essência do homem ("A substância do homem é a sua existência", parágrafo 43 de Ser e tempo.) e, nesta medida, o ser-no-mundo constitui uma estrutura fundamental que ainda que possa ser subdividida em diversas estruturas, e nós referimos três estruturas importantes, contudo constitui uma unidade. Ser-no-mundo, existência, Dasein, cuidado, temporalidade são constructos que remetem a um modo de ser que tem como característica fundamental ser uma estrutura prévia de sentido. 
No relacionar-se (comportar-se) com os entes disponiveis como puramente presentes, se estabelece uma relação com os objetos que produz um encobrimento. Quando se utiliza o conceito de objeto fica oculta a dimensão central de serno-mundo que vem implícita no lidar com os entes disponíveis. É por isso que na relação de objeto se encobre o que no comportamento deveria mostrar-se: que o objeto não é o todo. $\mathrm{E}$ isso perturba. Perturba-nos em nossa relação de objeto ou perturba-se o nosso modo de ser-no-mundo, nosso mundo?

Ainda que na obra de Freud apareça com pouca frequiência a expressão relação de objeto ou algo semelhante, na tradição inglesa essa expressão adquiriu uma importância de primeira linha e a partir daí seu uso se difundiu pelo mundo. Ainda que essa expressão seja universalmente compreendida, ela trouxe, no entanto, graves problemas para o seio da psicanálise. É, sobretudo, nas implicações teóricas que a relação de objeto causa dificuldades muito grandes, porque traz consigo uma profunda ambigüidade. Esta se situa em dois niveis: num, se apresenta a questão do vínculo entre relação de objeto e mundo, particularmente sob o aspecto do que é determinante entre perturbação da relação de objeto e perturbação do mundo, no outro, a dificuldade reside no próprio sentido de objeto, na medida em que ele sugere uma espécie de plenitude e de posse, quando, na psicanálise, tem extrema importância a questão da falta de objeto. Este segundo nível foi trazido ao domínio da discussão pela expressão lacaniana de objeto perdido, tema desenvolvido no Seminário $4{ }^{1}$

A questão que eu quero examinar implica uma série de elementos com os quais se deve tentar resolver um problema essencial: ouve-se dizer muitas vezes que a nossa perturbação na relação com os objetos é consequiência da perturbação de nosso mundo. Não é a relação perturbada dos objetos que perturba o nosso modo de ser-no-mundo, mas é uma falha de nosso modo de ser-no-mundo que interfere em nossa relação com os objetos. Dessa questão decorrem consequiências extremamente importantes. Em primeiro lugar, e essa é a objeção fundamental que vem do campo daqueles que trabalham com a clínica, se propōe o seguinte: se a perturbação na relação com os objetos é conseqüência da perturbação de nosso ser-no-mundo, então toda tentativa de uma terapêutica de nossa relação com os objetos passa a depender da possibilidade de nós pormos em ordem a perturbação sofrida pelo nosso modo de ser-no-mundo. Ora, se fôssemos exigir uma terapia do nosso modo de ser-no-mundo, estaríamos colocando um problema sério sobre que tipo de terapia seria esta. Isso não merece ser analisado mais longamente porque não entra nem mesmo em questão. Como então resolver este problema de que há um vínculo entre mundo na analítica existencial e relação com os objetos na psicanálise?

Nós sabemos que o lidar com os entes disponiveis, isto é, com os objetos que nos rodeiam em sua instrumentalidade, sabemos que esta relação é um elemento constitutivo do nosso modo de ser-no-mundo de uma maneira temporal e finita.

1 "Freud insiste no seguinte: que toda maneira, para o homem, de encontrar o objeto é, e não passa disso, a contínuação de uma tendência onde se trata de um objeto perdido, de um objeto a se encontrar." (LACAN, Jacques. O Seminánio. Livro 4, A relaçāo de objeto. Rio de Janeiro: Jorge Zahar, 1995, p. 13.) 
Mas, quando nós descrevemos esse lidar com os entes disponíveis não estamos descrevendo uma instância empírica. O que estamos efetivamente fazendo é construir uma espécie de estrutura que possa ser vista como algo que sustenta os elementos empíricos que podem aparecer no nosso modo de relação com os objetos, seja de uma maneira normal, seja de uma maneira perturbada.

Se falamos, portanto, do lidar com os entes disponiveis como elemento que compõe o nosso modo de ser-no-mundo e, desta forma, integra a nossa existência, e se consideramos tanto existência, como Dasein, como modo de ser-no-mundo, constructos estruturais, propriamente afirmar que em algum destes elementos estruturais se produziu uma perturbação, se produziu uma desordem, significaria que com isso se estaria pondo em jogo aquilo mesmo para o qual serviu essa construção de estruturas. Isto é, dar uma espécie de elemento constante que é constituinte da condição humana. Há, portanto, aí, a afirmação de um nivel que faz parte daquilo que podemos chamar a estrutura prévia de sentido que dá unidade ao nosso modo de ser.

Se o lidar com os entes disponiveis pudesse ser perturbado e então surgiria disto uma relação de perturbação de objeto do nosso mundo, estariamos dizendo que efetivamente no nivel de um tratamento da nossa relação com os objetos, ou de uma terapia de nossa relação com os objetos, ou de uma clínica da nossa relação com os objetos, estariamos dizendo que ai também se exigiria uma clínica do nosso modo de lidar com os entes disponíveis, enquanto estrutura do modo de serno-mundo, enquanto característica do constructo Dasein. Isso parece impossivel por muitas razões. Em primeiro lugar, porque se pretendemos uma descrição central da condição humana através do constructo Dasein e de seus diversos elementos, incluído o lidar com os entes disponíveis, temos uma pretensão de completude, isto é, de dar as coordenadas essenciais que constituem a existência. Isto de uma maneira formal, de uma maneira construída.

A perturbação não se fará no nível da construção formal da estrutura que constitui a existência. Se fosse possivel uma perturbação nesse nivel, o constructo Dasein, a existência, ou o ser-no-mundo estaria, de certo modo, incompleto e teria algum tipo de vínculo com uma dimensão empírica que é negado radicalmente pela analítica existencial. Já que não pode haver uma perturbação da relação do lidar com os entes disponiveis, precisamos procurar as razões porque a relação de objeto está perturbada e se continuarmos afirmando que esta relação de objeto está perturbada porque há um vinculo com o lidar com os entes disponiveis, então deve ser introduzido um elemento que até agora não foi acentuado por nenhum autor. Isto é, não é o mundo no lidar com os entes disponiveis que é perturbado, produzindo então uma perturbação na relação de objeto, mas através da experiência do lidar com os entes disponíveis se revela uma dimensão no cotidiano lidar com os entes no presente, uma dimensão que, nesse lidar cotidiano com os entes no presente, abre algo maior, ou algo mais amplo do que simplesmente o estar ocupado com os entes no presente e de certo modo lidando ai com os entes disponiveis. Que algo maior é esse? 
É recorrente na obra de Heidegger a afirmação que o Dasein tende de um modo radical para o encobrimento. Isto quer dizer que no seu lidar com os entes disponíveis o homem exerce como que uma atividade de encobrimento, como também nos outros aspectos de sua relação com os entes simplesmente existentes e, no compreender-se em vista de sua existência, também se encobrem elementos fundamentais.

A perturbação nas relações de objeto, portanto, não provém de uma perturbação do lidar com os entes disponiveis. Mas, de alguma maneira, o indivíduo é posto, através de suas relaçōes de objeto diante de algo desconhecido, diante de algo estranho, diante de algo que não acontece constantemente, diante de algo que revela faces novas, diante daquilo que podemos chamar do oposto ao familiar dos entes disponíveis, que seria o estranho ou, então, o sinistro. A perturbação, portanto, näo vem de aspectos negativos produzidos no lidar com os entes intramundanos, mas se produz a partir de um plus, de um mais que é dado experimentar, justamente, como condição total da existência. No entanto, esse algo mais, esse plus, não é algo que nos apazigua, algo que nos tranqüiliza, mas é um como que rompe a atitude cotidiana, a atitude do lidar no presente com os entes intramundanos, causando uma série de reações diferentes. Essas reações podem se desenvolver em graus diferentes conforme o tipo de pessoa que passa por essa experiência. Todos nós passamos por essa espécie de visita do estranho, que nasce para além daquilo que se mostra na relação com entes intra-mundanos e os entes disponíveis. Só que cada um é capaz de suportar até um certo nivel esta experiência. Alguns sofrerão na sua relação empirica com o mundo dos objetos perturbações, terão problemas que se poderão revelar através de manifestações traumáticas, através de diversos tipos de sintomas que se revelam na perturbação da relação de objeto.

Isso não significa que o mundo dessas pessoas, em sua totalidade, que sua existência se tenha perturbado ou, de certo modo, descomposto. Não significa isso. É que na existência como um todo se filtraram, ou nos interstícios, em certos momentos, vazaram aspectos ligados à experiência como um todo que são estranhos, não familiares, não costumeiros e por isso, no nivel da relação com os objetos se produz uma perturbação. Assim, para podermos efetivamente pensar numa dupla estrutura, por exemplo, na psicanálise, como o faz a analítica existencial, em que em geral todos os autores atribuiram a perturbação na relação de objeto a uma perturbação primeira do mundo, nós precisamos ver que essa perturbação primeira do mundo não é de caráter negativo. Pelo contrário, ela amplia a nossa experiência rotineira do cotidiano e faz com que sejamos como que surpreendidos por aquilo que poderiamos chamar o estranho, o sinistro, aquilo que nos desenrai$\mathrm{za}$, pois, é aquilo que tendencialmente encobrimos. É desta maneira que nos visita, como Heidegger diz no Que é metafisica?, o nada. É desta maneira que nos cerca a angústia. Mas nós não vivemos constantemente na angústia, na relação com os entes disponíveis no nível existencial. Não. Normalmente nós estamos ocupados com os entes intramundanos, junto dos quais estamos e esquecemos as condições da faticidade e as condições da existência ou da futuridade. Quando algo da faticidade ou da futuridade introduzem este elemento surpreendente no 
nosso lidar com os objetos intramundanos no mundo cotidiano, nos sentimos como que atingidos por algo que não esperávamos. Justamente, este algo ainda faz parte da existência, numa medida em que ela, antes, estava encoberta. Se nós suportamos ou não a experiência do nada, a experiência da angústia que nos vem a partir da experiência da totalidade da existência, é úma outra questão. E as perturbações no nivel dos objetos resultaram ou não conforme nós somos capazes de suportar a experiência do nada, a experiência da angústia.

Com estas observações estamos respondendo a uma série de problemas que haviam ficado sem solução desde Binswanger com a sua análise do Dasein, na medida em que a objeção fundamental era a seguinte: se no nível da relação de objetos, se no nível da experiência clínica existem perturbações que devem ser remetidas a um tipo de perturbação de nosso mundo, então para que serve uma simples clínica dessas situações da relação de objeto no mundo cotidiano da neurose, da psicose, da perversão? Nós teríamos que, para poder tratar isso, tratar antes a própria existência, teríamos que, de certo modo, ter uma clínica para o nosso modo de ser-no-mundo. Esta questão aparece recorrente na Daseinsanalyse de Binswanger. Nisso se revela algo muito mais radical. Se nós interpretarmos esta questão como até agora o tentei fazer de uma maneira positiva, por algo novo que se revela, pelo sinistro, pelo estranho que nos visita, então, certamente, faremos duas descobertas fundamentais e que se opõem, radicalmente, àquilo que poderíamos confusamente aproximar de Marx e Freud. Vamos fazer a experiência de que, como na existência, sempre aparecerão, em sua experiência, elementos estranhos, singulares, inusitados. Se sempre aparece isso, sempre haverá algum tipo de perturbação que nos irá invadir no cotidiano das nossas relações de objeto e eventualmente perturbar esta relação. Isso significa apenas, do ponto de vista psicanalítico, por exemplo, que a análise é interminável, que de certo modo não existe cura definitiva. Porque cada vez que o estranho, o sinistro, o não acostumado aparecer através do nada, através da experiência da angústia, se formarão, novamente, no nivel da pessoa, no nível do cotidiano, perturbações, e elas serão novamente revistas e, desta maneira, transitoriamente se fará não uma cura definitiva, mas simplesmente uma superação daqueles momentos fundamentais em que o sofrimento que aparecera se tornara insuportável. Disto que eu disse, portanto, se conclui que a psicanálise é interminável e que propriamente a cura não existe na psicanálise. Se nós quiséssemos impedir para sempre o surgimento de uma perturbação na relação de objeto, teríamos que nos curar da existência humana, isto é, tirar da existência aqueles elementos que dela surgem, enquanto ela é um modo de ser-no-mundo. Ora, curar a existência humana deste novo que pode filtrar-se nos interstícios do dia-a-dia, como o nada, a angústia, o sinistro ou o estranho, querer eleminá-los, seria truncar a existência. Sob este ponto de vista estaríamos eliminando a própria condição humana.

Portanto, vendo positivamente, a condição humana sempre será uma condição finita, não totalmente transparente e por isso mesmo será imprevisivel como pode agir sobre nós aquilo que encobrimos enquanto existimos radicalmente. Mas, certamente, não é a perturbação do nosso mundo que produz a perturbação na relação de objetos, mas é o novo, que de vez em quando emerge em nossa expe- 
riência da existência, que não é suportado no nivel em que a clínica pode trabalhar as perturbações. Fundamentalmente, esta é a questão central. Assim conseguimos fugir de grande parte das objeçōes que se faziam contra essa duplicidade da perturbação do mundo e da perturbação na relação de objeto e também se descobre, se deduz, que a psicanálise é interminável e que não existe a cura definitiva, porque o Dasein continua sempre de novo nos preparando surpresas.

\section{IV}

Os modos fundamentais do estar-ai que representam uma modificação da temporalidade, no seu todo, são designados por Heidegger como existência. E existência é um modo fundamental do estar-ai. É neste sentido que Heidegger pode dizer que "a substância do homem é a sua existência". O constructo estar-aí que Heidegger descreve através do representar o puramente existente, o lidar com o ente disponivel e o compreender-se em vista da existência, representa a hipótese da ontologia fundamental de Heidegger ou a hipótese fundamental da analítica existencial. É claro que quando nós falamos, distinguindo os dois níveis a que me referi anteriormente, o nível empírico em que aparecem fenômenos que podem ser abordados pela clínica e o nível existencial que tem uma certa qualidade transcendental que seria essa estrutura fundamental da existência, nós estamos trabalhando, nesse segundo nivel, com uma espécie de construção. Daí que a hipótese, dentro da hipótese maior do lidar com o ente disponivel, das relações com os objetos no modo de ser-no-mundo, também representa uma construção.

Ora, toda construção é algo que não é a realidade como tal. Toda construção é uma espécie de teoria. Entre a relação de objeto, que nós percebemos perturbada no nível clínico e a hipótese do lidar com os entes disponiveis, existe um espaço vazio, isto é, existe uma instância que deve ser transposta. Como ir do lidar com o ente disponivel até as manifestações, por exemplo, numa neurose em que aparecem as perturbações na relação de objeto, como ir entre um polo e outro significa ter que dar conta do preenchimento desse espaço. Esse espaço só se pode preencher através de uma teoria. É, justamente, essa teoria que estaria presente na afirmação de que a perturbação nas relações de objeto é produto da perturbação do lidar com o ente disponivel, portanto, uma perturbação do mundo como estrutura.

A afirmação de que a perturbação com o mundo precede a relação de objeto e condiciona essa relação de objeto é uma afirmação que deveria ter uma base teórica. Só assim nós preenchemos o vazio entre lidar com o ente disponivel e o aparecimento da perturbação nas relações de objeto.

Naturalmente, nós podemos perguntar-nos o seguinte: se o lidar com o ente disponivel é uma hipótese, dentro do constructo do Dasein, o que significa nós falarmos em perturbação disso que é colocado na hipótese, lidar com o ente disponivel? É muito difícil podermos dizer que existe uma perturbação em estruturas que são descritas e apresentadas hipoteticamente como elementos fundamentais da existência. As perturbações deveriam se dar na existência como tal e não em elementos que são apresentados por esta hipótese da teoria da existência. Isso porque a teoria da existência não é uma teoria empírica. Se ela não é uma teoria 
empírica, ela necessariamente é um constructo que nós arrumamos para poder falar de uma dimensão que presumimos anterior à relação de objeto no nivel empirico.

Dessa maneira, não podemos, através da afirmação de que perturbação do mundo produz a perturbação nas relações de objetos, fazer uma passagem empirica. Afirmar que a perturbação das relações de objeto é produto da perturbação das relações do mundo, parece uma afirmação de caráter empírico. Isso também é uma hipótese e não é a descrição de uma realidade. Porque nós temos, nas duas pontas, dois niveis diferentes, não podemos aproximar os dois niveis em que um nivel é o nível da experiência e o outro é um nível a partir de um constructo. Não podemos fazer a passagem através de dados da experiência. Isso torna muito problemática a hipótese de que a perturbação nas relações de objeto seja um produto da perturbação do mundo.

Como fazer então? É justamente aqui que está o núcleo da questão que eu já mostrei na análise acima. Como se constitui esse mundo? Como podemos afirmar algo assim, se nós não temos uma passagem empírica desse elemento existencial, transcendental, para o elemento empírico? Em todo caso, fazendo uma espécie de inversão da afirmação de que a perturbação está no constructo ser-no-mundo, portanto, no lidar com o ente disponivel, para uma afirmação de que desse ser-nomundo, no lidar com o ente disponível, algo escapa e que é uma presença positiva, naturalmente, como construção. Que presença positiva é esta? Ela é a hipótese de que no lidar com o ente disponivel estão presente elementos maiores que o simplesmente lidar com as coisas junto aos entes intramundanos. Nessa hipótese está presente também a idéia de que com isso encobrimos aspectos que, de certo modo, de si não aparecem, mas que em momentos privilegiados podem aparecer. Portanto, se a partir desses momentos privilegiados fizermos uma passagem para a perturbação nas relaçōes de objeto, novamente estaremos fazendo uma passagem da estrutura do mundo para a estrutura de uma experiência empírica. Entretanto, nesse segundo momento, nós não estamos negando que está se desarticulando um constructo, uma estrutura, uma hipótese. Nós apenas estamos dizendo que a hipótese do lidar com o ente disponivel, como um dos elementos da modificação da temporalidade, que essa hipótese não expressa tudo o que, num primeiro momento, vemos na expressão lidar com o ente disponivel. Isto é, não é apenas o estar junto dos entes, perdido no presente, mas este estar-junto-dos-entes, perdido no presente, é também uma manobra com a qual excluimos aspectos que de certo modo são perturbadores e que vêm de outras instâncias que não o presente; que vêm do futuro e do passado, como se a existência (futuro) e a faticidade (passado) não tivesse uma ação simultaneamente junto com o presente, sobre o nosso modo de nos relacionarmos com os objetos. Mas, de certo modo, nós excluímos por uma espécie de encobrimento ou uma fuga de nós mesmos, esses dois aspectos que podem trazer para o mundo familiar da relação com o ente disponível, elementos estranhos, elementos inesperados, elementos assustadores, aquilo que denominamos o sinistro. Portanto, se nós olharmos positivamente as perturbações na relação de objeto como resultado do lidar com os entes disponiveis, nós podemos incluir esses outros aspectos e são esses outros aspectos que produzem uma 
perturbação na relação de objeto. Não porque representam uma perturbação do mundo, mas porque representam o mundo como totalidade que nós encobrimos, quando ficamos numa pura relação com os entes no presente.

Justamente, o mundo como totalidade não nos aparece sempre. Heidegger tem exemplos notáveis sobre quando aparece esse em sua totalidade, exemplos, sobretudo, registrados na conferência Que é metafísica? É assim, então que terminamos trabalhando com a hipótese da origem da perturbação nas relações de objeto, a partir do modo de ser-no-mundo que não exige uma desarticulação do nosso constructo, pelo contrário, nele existem elementos que nós conscientemente, ao fazermos esse constructo, sabemos presente. Eles são elementos que fazem parte da temporalidade mas que são elementos do futuro e do passado, da existência e da faticidade que, no nosso lidar com os objetos no presente, são encobertos. E quando eles aparecem em momentos em que se produz uma espécie de totalização da existência no nivel do cotidiano, no nivel da experiência empírica, se produz uma espécie de confusão, de reação anormal, uma espécie de tentativa de também fugir aí, disso que é a experiência da totalidade. $\mathrm{E}$ assim isso aparece como neurose ou como outras manifestações de caráter patológico. É assim que temos, então, a afirmação de que há uma relação entre as perturbações que são atingidas no nivel clínico e o mundo que Heidegger descreve como estrutura prévia de sentido. É assim que essa ligação que fazemos, tem como resultado não podermos ser contestados com a afirmação feita antes: De nada adianta tratar perturbações no nivel de objeto se não tratarmos perturbações que as causam, que são dadas no nivel da perturbação do mundo, no modo de ser-no-mundo. Efetivamente, nada há perturbado nesse nível analítico-existencial do ser-no-mundo. Pelo contrário, nesse nivel são apanhados elementos que nós tendencialmente encobrimos, nos momentos de angústia, nos momentos de fuga de nós mesmos em que nós nos perdemos no cotidiano junto aos entes. Esses elementos quando fazem o seu aparecimento ou sua manifestação, no nivel empirico, produzem reações que poderemos chamar de patológicas.

Então, não existe necessidade de dizermos que com uma teoria que coloca como elemento fundante a analítica existencial, nós temos, de certo modo, que dar conta de como se faz a modificação desse nivel profundo. Nesse nivel profundo não é preciso fazer nenhuma modificação, pois é nele, em sua estrutura completa que nós encobrimos em parte, na nossa tendência para o encobrimento, que se enraizam experiências que num nível empírico, não são suportadas e diante das quais reagimos de uma maneira traumática, ou neurótica. É importante podermos encontrar o caminho, ao menos aproximado, nessa direção, porque com isso fugimos das dificuldades que têm a maioria dos teóricos da psicanálise que se baseiam na analítica existencial. Com isso fugimos das contradições e dos paradoxos que com eles se apresentam. Sobretudo, as objeções que sofrem constantemente de que apresentam dois niveis de perturbação e apresentam apenas a terapia para um tipo de perturbação e não para a outra perturbação. Não existe a possibilidade de fazer a terapia para o modo de ser-no-mundo. Fazer a terapia do modo de serno-mundo seria exatamente ter que fazer uma nova construção como hipótese do que é o ser humano como Dasein, como existência, portanto, seria, de certa ma- 
neira, negar exatamente aquilo que se coloca como uma questão essencial na analítica existencial, a de que somos entes finitos que nunca se abarcam na sua totalidade, na medida em que apanhada como totalidade, a existência - o futuro, a faticidade - o passado e o estar junto dos entes, faz parte de uma experiência esporádica, de uma experiência transitória do ser humano enquanto cuidado.

É assim que podemos repetir aquilo que já no início dissemos: que o modo positivo de ver as manifestações que aparecem no nivel da perturbação na relação de objeto, o modo positivo de ver como isso é produzido através da experiência existencial, nos mostra os limites de nós mesmos no dia-a-dia; nos mostra a impossibilidade de nós sermos inteiramente transparentes. No fundo, mostra-nos a impossibilidade de nos prevenirmos contra essas perturbações na relação de objeto. Isto é, mostra que é impossivel a cura na psicanálise, ou como diz Freud, a psicanálise é interminável. Nunca estaremos prevenidos contra a manifestação da angústia que se filtra através de nossa experiência da qual queremos fugir e a qual queremos encobrir. Mas quando ela aparece na experiência da totalidade, ela termina produzindo, no nivel da relação de objeto, possíveis perturbações. É isso fundamentalmente que queremos propor com a inversão dessa afirmação de que é uma perturbação do mundo que produz uma perturbação da relação de objeto. Pelo contrário, é o mundo como totalidade que se manifesta esporadicamente na existência, através de experiências radicais, através da experiência da angústia, que nós não suportamos no nível empírico, no nível do cotidiano e por isso aparece como uma experiência traumática, uma experiência neurótica no plano da relação de objeto.

\section{2 - Finitude do Dasein e a desconstrução da relação de objeto}

\section{V}

Quando a psicanálise se refere à relação de objeto, ela, ao mesmo tempo em que trabalha com um conceito recorrente na construção da relação eu-mundo, ela se confronta com conteúdos múltiplos que vêm expressos nesse termo técnico. Certamente, a psicanálise não consegue dar conta de todos os elementos que devem ser acionados para que a expressão relação de objeto manifeste sua complexidade. Num primeiro momento, exprime-se o simples vínculo que representa a passagem do sujeito para o objeto. Como se a solução dessa passagem não oferecesse já suficientes dificuldades teóricas, a relação de objeto se configura na psicanálise mais com um sentido afetivo, emocional. É preciso, portanto, introduzir o que representa o movimento pulsional em direção do objeto. As dificuldades começam quando queremos descrever este como da passagem para o objeto que constitui a relação.

Tradicionalmente, coloca-se o desejo como o vetor que leva a vontade ou 0 afeto em direção de algo. Esse algo, por sua vez, quando para ele se inclina o desejo, já não é mais simplesmente um objeto neutro. Nossa inclinação para ele já se dá num quadro que não é simplesmente real. No desejo o objeto toma a forma de um imaginário e o contexto no qual se realiza esse movimento tem um caráter simbólico. 
Tratamos, no entanto, aqui, ao falarmos da relação de objeto no contexto da psicanálise um quadro todo da relação que aparece situado na outra cena. $\mathrm{E}$ aquilo que aí se desenrola não é uma abstração psicológica. A relação de objeto representa o lugar de uma eficácia. Aí se mostra o desejo inconsciente que em geral não é reconhecido. Pois aparece mais como sintoma, sendo assim a expressão censurada de um desejo não reconhecido, isto é, recalcado. Mas ao estabelecermos o contexto da outra cena teríamos que reconhecer-nos como sendo nós mesmos aquilo que da outra cena se revela como sintoma.

Os eventos que introduzem a relação de objeto no inconsciente se apresentam com uma dupla face: de um lado, o trauma nos dá elementos epistemológicos que podem ser ligados até à idéia de causalidade; mas, de outro lado sabemos que 0 trauma é apenas ocasião para que se estabeleça a relação de objeto, mas efetivamente ele nos leva a uma dimensão de ordem prática. Ele se mostra eficaz apenas no momento do sintoma. Portanto, o que efetivamente acontece na relação de objeto não se situa na ordem da causalidade, sai do contexto da natureza, é independente dos fenômenos físicos e assim revela uma espécie de automatismo que se desenrola na outra cena.

A relação de objeto, portanto, não nasce de uma simples representação de qualquer fato traumático, ela pode dar-se mesmo fora do campo de representação do sujeito, aparecendo, portanto, deslocada da rede significativa do sujeito. É por isso que não podemos separar a relação de objeto da idéia da outra cena, pois ela é sempre uma desordem produzida na trama simbólica do sujeito. Por isso se converte em sintoma.

Do que dissemos até agora pode-se inferir, sem dificuldade, que existe um problema naquilo que a expressão relação de objeto diz, à primeira vista, e aquilo que efetivamente aí está em questão para o inconsciente. A melhor maneira de localizarmos o problema introduzido por uma expressão näo inteiramente adequada é desconstruir a expressão. A desconstrução significa retirar da compreensão e da circulação comum esta expressão e com ela retornar às origens onde ela se gerou. Portanto, desconstruir pode significar despir a expressão de sua universalidade aceita e ressituá-la na nudez e no desamparo de sua origem.

Mas, entregar-nos à tarefa da desconstrução de uma expressão tão essencial coloca-nos, no mínimo, em confronto com todo o edifício epistêmico da psicanálise e, de outro lado, nos exige recursos teóricos articulados a partir de um outro contexto. Se na análise que segue empreendemos esta desconstrução fazemo-lo, por várias razões que primeiro nos vêm da autoridade da obra de Freud, de Lacan e de Heidegger. Poderíamos dizer simplesmente que "relação de objeto" representa exatamente uma simetria entre o sujeito desejante e o objeto desejado. Ora somente existe psicanálise, existe recalcamento, existe sintoma, porque o ser humano está constituído precisamente pela falta de objeto. Nascemos culpados não porque somos uma obra imperfeita, mas porque nos debitamos como imperfeição o objeto perdido. É assim que pela desconstrução se desfaz o conceito de relação objetal, caindo também assim a idéia de completude, de preenchimento. No caminho da desconstrução somos capazes de recuperar para a clínica o legado originário de Freud que ele embutiu na palavra Trieb (pulsão) que justamente se 
constitui em Lacan como desejo, pela falta de objeto, pela nostalgia do objeto perdido.

Falamos, acima, de um quadro teóríco no qual teria que ser feita essa desconstrução do pressuposto epistêmico que se transmite na expressão "relação de objeto". Ao analisarmos, em momento anterior, a questão da hipótese da perturbação na relação de objeto, introduzimos alguns elementos centrais da analítica existencial. Vimos ai que a estrutura do cuidado enquanto ser do Dasein se estrutura através do ser-adiante-de-si, já-sempre- no-mundo e junto-dos-entes. Heidegger designa esta tríplice estrutura com os termos existência, faticidade e decaida. E nesta estrutura o elemento central se constitui pela possibilidade diante do ser-para-a-morte, como impossibilidade de qualquer nova possibilidade. Assim, também a faticidade se dá como a inelutabilidade do ter-que-ser exatamente referido a essa impossibilidade, sem poder repor nada, sem receber a simetria de um objeto, mas apenas o destino da ausência de objeto, da falta. E Heidegger continua descrevendo a situação da decaída em que, junto dos entes, procuramos, em sua presentidade uma simetria entre sujeito e objeto que encubra nossa condição de sermos constituídos precisamente pela perda dos objetos, pela falta, pela nostalgia do objeto perdido enquanto estrutura existencial.

Não precisamos expor em mais detalhes isto que constitui como modificação da temporalidade, o modo de ser na finitude do Dasein. Falamos numa articulação de três modos fundamentais do ser-aí: o representar o ente puramente existente, o lidar com o ente disponivel e o compreender-se em vista da existência. Ainda que esses três modos de ser se dêem imbricados numa unidade, as conseqüências dessa unidade tornam-se insuportáveis e assim nós tentamos pensá-los em esferas separadas. Pois, dessa maneira encobrimos as relações que se estabelecem entre eles e que propriamente determinam nosso comportamento existencial. Na relação de objeto se encobre um comportamento existencial que aponta para uma transcendência em cuja ponta näo aparece objeto. É o simples ser-adiante-de-si em direção da última possibilidade. A existência é essa transcendência e como tal ela não se constitui de relações com objetos, mas de comportamento - Verhalten - a partir de cuja dimensão significativa, o ser-no-mundo, o ter-que-ser, o sentimentode-situação e o compreender, passam a ser os existenciais a partir dos quais poderemos pensar corretamente as relações de objeto. Elas sempre serão de caráter segundo, chegam depois e não têm como função primeira fixar uma simetria entre sujeito e objeto, mas, apontar com a busca dessa simetria, para aquilo que com ela encobrem, em nome da completude e do preenchimento, a falta de objeto, a impossibilidade de um objeto correlato da angústia da finitude, sintoma básico do objeto perdido para sempre. ${ }^{2}$

2 “É surpreendente ver que, no momento em que faz a teoria da evolução instintual tal como esta se origina das primeiras experiências analiticas, Freud nos indica que o objeto é apreendido pela via de uma busca do objeto perdido" (Lacan, op. cit., p. 13). 
Para chegarmos ao núcleo do problema da desconstrução da relação de objeto e podermos então propor uma revisão de um conceito tão central na psicanálise, vamos introduzir a questão do comportamento como transcendência, de vital importância para radicalizar o problema do conhecimento que aqui está em questão. Não se trata de problematizarmos apenas o que poderia significar a relação de objeto enquanto representa um lugar que para a psicanálise não possui somente uma função teórica. Já falamos do caráter afetivo que se oculta nessa expressão. Mas na medida em que esse elemento não é uma simples inclinação da vontade ou do amor, mas algo ligado à esfera da pulsão, temos aí um componente de caráter cognitivo não representacional, mas que resulta de um modo global de o ser humano se mover no mundo. Trata-se, portanto, de um conhecer que se apresenta como um modo-de-ser e neste modo de ser todo o movimento em direção do objeto recebe uma tonalidade afetiva que precede a relação epistêmica propriamente dita.

Possuímos diversos recursos para dar conta desse modo-de-ser-no-mundo anterior à relação sujeito-objeto que, ainda que já uma forma de conhecimento, contudo, apresenta em seu núcleo um elemento afetivo e prático. Podemos trabalhar com a idéia de que a estrutura fundamental do lidar com os objetos que conhecemos é constituída por uma tonalidade afetiva que, ao mesmo tempo em que é uma compreensão, representa também uma espécie de investimento emocional. Se formos desenvolver esta modalidade de análise chegaremos a um ponto onde iremos descobrir que o movimento significativo fundamental da existência consiste num compreender-se e explicitar-se de modo prático e operativo em que todos os elementos de uma relação de objeto são descobertos como enraizados numa totalidade que se articula ao modo-de-ser-no-mundo como existência. Nesse modo de compreender a relação de objeto aparece propriamente a partir de sua ausência no todo ou ao modo da privação, modalidade pela qual aquilo que buscamos com o movimento da pulsão só aparece como objeto quando falta.

Se formos seguir essa linha de desenvolvimento podemos concluir que a relação sujeito-objeto no conhecimento constitui uma espécie de recorte daquilo que imaginamos ou representamos como posse de algo presente e portanto, permanente. Assim, toda a operação epistêmica constitui de certo modo, uma luta contra uma espécie de totalidade significativa da qual não somos donos, mas na qual nos movemos e pela qual somos constituídos. Dessa totalidade, justamente, enquanto existência, na expressão de Heidegger, um ser-adiante-de-si-mesmo, nos ameaça sempre a possibilidade da falta, a inutilidade do fixarmo-nos nos objetos pela representação, a contingência de qualquer ente com que nós lidamos e em que investimos.

Por esse caminho a desconstrução da relação de objeto consiste em situá-la no todo onde ela é precedida por um comportamento ou um modo-de-ser que fragiliza a relação. Quando falávamos do modo-de-ser-no-mundo e da perturbação na relação de objeto nos referiamos a uma espécie de caráter insuportável da percepção de que a solidez da relação de objeto era desfeita pela intervenção do estranho que se anunciava ao modo daquilo do qual estávamos em fuga e que nos 
vinha do futuro e do passado. Esse elemento de perturbação é o que propriamente opera na angústia diante da perda real, da possivel perda, ou da perda imaginada de objetos que pensávamos garantir a nossa plenitude ou nosso preenchimento.

Se o acontecimento que assim descrevemos se desse apenas numa esfera epistêmica não se produziria propriamente nada do efeito que descrevemos. Não se trata nem simplesmente de um conhecer nem de um querer, mas de um movimento da pulsão vestida de desejo que mostra ao ser humano que ele não é autônomo como se poderia presumir a partir da liberdade e da razão. A busca do objeto, na relação de objeto representa um movimento do desejo que carrega em si já sempre uma espécie de informação de um obscuro objeto do desejo nunca atingido, cuja falta deveria ser substituida por esse ou aquele objeto. É nisto que consiste, propriamente, a duplicidade do processo que está por trás da relação de objeto. Na outra cena ou na esfera do outro, aparece a incompletude que nos atribuímos como culpa e que se junta, como sintoma profundo, ao lado do outro sintoma em que qualquer elemento recalcado procura se mostrar.

Há portanto, na relação de objeto, algo que não se expressa com esta fórmula e que aparece como o estranho, sendo esse propriamente o limite que não quiséramos aceitar no nosso desejo. Assim, todo elemento censurado de um desejo que não se reconhece, o recalcado que é o sintoma de um objeto que não foi alcançado no caminho do desejo, tem como a precedê-lo a presença do sintoma de que todo o objeto é de certo modo perdido, porque se situa numa cadeia de significantes que sempre permanecerá incompleta. $\mathrm{O}$ estranho é, propriamente, a invasão do cotidiano estar-junto-dos-entes (que de modo algum é apenas de caráter cognitivo), e isso não consegue integrar-se no campo da representação do sujeito. No entanto, esse estranho é a verdade do sujeito, na medida em que o destitui de um lugar em que se representa na posse constante dos objetos sem risco de perda. $O$ estranho se introduz, portanto, como uma totalidade finita que negamos quando queremos consolidar a posse dos objetos na relação de objeto. A proposta de desconstrução da relação de objeto pretende exatamente situar na relação de objeto, algo que a expressão encobre.

Com a linguagem que até agora utilizamos conseguimos mostrar a estrutura que possibilita o recalcamento do objeto não atingido pelo desejo. Vimos também que esse encobrimento não é de caráter cognitivo ou composto de elementos epistêmicos, mas isso só foi possivel graças a uma espécie de desobjetivação da relação de objeto ou da remissão dessa relação ao espaço de um modo-de-ser-nomundo, em que nossa relação com os objetos possui um caráter de compreensão e de explicitação, portanto, um forma operativa mergulhada num contexto de tonalidade afetiva. Compreendido assim, o universo da outra cena participa desta cena do cotidiano. Não há, propriamente, uma distância entre a consciência e o recalcado onde se constitui o inconsciente. Há, efetivamente, uma experiência de ruptura, mas um fundo de totalidade mantém uma unidade do fenômeno psíquico. É como se se tratasse do verso e reverso de um processo: a consciência prende-se, na superfície, à certeza da posse dos objetos e neles investe e, no momento mesmo desse investimento, o desejo do sujeito instaura a outra cena em que se produz o espaço do inconsciente, onde o mesmo objeto que a consciência representa, 
perde o seu caráter de plenitude, de simetria entre o sujeito e seu objeto e passa a remeter pelo imaginário ao objeto perdido. Ai se instala a insegurança que a relação de objeto não expressa à primeira vista, pois, o elemento epistêmico sugerido na expressão reduz as proporções daquilo que está em jogo e que é um modo de ser no mundo em que um compreender-se e explicitar-se já sempre antecipam a posse do objeto pelo conhecimento e revelam que a condição humana é constituída a partir de uma antecipação da perda do objeto e de uma condição irremovivel de que assim estamos constituídos na faticidade. A possibilidade da perda de objeto nesse nível profundo constitui efetivamente o estado de destituição do sujeito, na medida em que sua plenitude falha diante da falta da completude do objeto. É isso, como acima dissemos que nós nos debitamos como culpa. A verdade do sujeito somente pode ser preservada na destituição pela falta e isso só é compreendido quando desconstruímos a linguagem com que a psicanálise continua falando da relação de objeto. Sua desconstrução nos mostrou as ilusões a que ela nos pode levar e 0 encobrimento que produz 0 fato de que o que constitui propriamente a outra cena é o sintoma do objeto perdido.

\section{VII}

Poderiamos tentar encontrar em soluções epistemológicas aqueles aspectos que abordamos, de uma certa maneira indireta, no que dissemos acima. Trata-se, no entanto, de esferas de análise, certamente, mais complexas do que simples problemas de conhecimento. Já, à primeira vista, uma problematização de como conhecemos não se adaptaria à complexidade daquilo que constitui o coração da psicanálise. A relação de objeto, ainda que ampliada até atingirmos o conceito de objeto perdido, contudo não dá conta daquilo que na psicanálise se apresenta para a constituição da outra cena, do que costumeiramente é apresentado como o latente em contraste com o manifesto. É que na própria idéia de objeto e ainda mais no conceito de relação, não conseguimos identificar a unidade do processo inconsciente que se situa para além de qualquer tipo de dualidade.

Ao explorarmos recursos da analítica existencial, já podemos perceber que nos situamos aquém da relação sujeito-objeto e abrimos um espaço novo para aquilo que se quer dizer com relação de objeto ou mesmo com a expressão objeto perdido. Nesse nível mais profundo a palavra relação toma a forma de comportamento e a dimensão ausente do objeto para o qual se dirige o desejo representa uma falha na questão do sujeito. É como se houvesse uma falha em ambos. Podemos falar de uma espécie de oco do objeto que a relação epistêmica procura encobrir, mas que, no nivel afetivo e emocional do investimento da libido, não consegue suportar, porque para ela é uma ilusão. Daí que o sujeito em falta ou destituído por esse oco de si mesmo vai além do objeto e se perde no imaginário.

Desse quadro termina aparecendo a problematicidade do conceito de relação que não possui aquela simetria de que acima falamos, particularmente porque passa por alto a dimensão fundamental do investimento libidinal, apresentando-se, assim, o sintoma. Não queremos com a desconstrução da expressão "relação de objeto", substituí-la simplesmente pela noção de "objeto perdido", pois, abrińamos apenas um lugar para a falta, sem no entanto, pensar a modalidade de ser que 
torna esta falta insuprimivel. O que se pretende mostrar é a própria estrutura do ser humano na medida em que, no nivel profundo da finitude, se pode conhecer aquilo que introduz o estranho da falta, sem cair numa espécie de dualismo em que 0 oco do objeto não preenche 0 oco do sujeito. Outra vantagem que resulta desta abordagem é que se não suprimimos as duas faces do oculto e do manifesto que aparece na linguagem, ao menos mostramos o lugar de onde se origina isso que, na linguagem da psicanálise, abordamos nos enunciados afirmativos ou negativos. $^{3}$

Se a falta de objeto pode ser pensada como uma espécie de sintese da psicanálise, ainda que traga dificuldades típicas do nivel epistêmico, com as sugestões que apresentamos, atingimos o núcleo daquilo que reúne numa tonalidade afetiva e emocional, a matriz da psicanálise. Com isso não estamos fazendo uma espécie de psicanálise de profundidade ou mesmo uma psicanálise filosófica. Estamos apenas apontando para certas condições que permitem sustentar o discurso sobre a falta. Estamos nos movimentando como que numa região de onde se alimenta 0 discurso sobre a falta. É o que, na filosofia de Heidegger, chamariamos de espaço hermenêutico que se dá como enquanto hermenêutico. $O$ enquanto do enunciado com que lida a psicanálise é o enquanto apofântico.

Se fôssemos exprimir, através de camadas essa constituição que constitui e acompanha o ser-no-mundo, poderíamos falar de um enquanto como estrutura do mundo, da compreensão, dos enunciados hermenêuticos e dos enunciados apofânticos. É claro que a psicanálise como ciência se move na última das camadas. Entretanto, aquilo de que fala faz parte de um comportamento em que nos compreendemos e nos explicitamos e não apenas se liga a uma relação entre sujeito e objeto. Nessa camada segunda, o latente e o manifesto, o cognitivo e o elemento do desejo podem ser compreendidos na unidade de um modo de ser. Quando falamos então de perturbação da relação de objeto queremos de fato referir-nos a uma experiência que acontece contra a idéia de plenitude sugerida pelo objeto. Essa perturbação é simplesmente a insinuação de um inesperado, de um estranho, de um limite, da castração, que recusamos no nosso próprio modo de falar apofântico.

É assim que podemos presumir a presença desse estranho onde aparece, em nosso discurso de objeto, uma lacuna, uma falha ou, simplesmente, um vazio. Por mais surpreendente que possa parecer, é pela linguagem que introduzimos e ao mesmo tempo sustentamos essa dupla face do latente e do manifesto, do estranho e do familiar.

Falamos acima de muitos aspectos que apresenta a ultrapassagem da barreira do simples estarmos envolvidos num comportamento com os objetos disponiveis no nosso presente. Acentuamos sobretudo, o caráter angustioso e ameaçador que nos vem da existência enquanto adiante-de-si-mesmo e da faticidade como o jásempre-estar-jogado. Poderiamos desdobrar o que se expressa de maneira tão concentrada, mas é suficiente para a nossa tarefa de desconstrução, mostrar que a

3 "Nâo podem deixar de ver que também aqui o objeto tem uma certa funçāo de complementação com relação a alguma coisa que se apresenta como um furo, até mesmo como um abismo na realidade" (Lacan, Jacques, Op. cit., p. 22.). 
relação de objeto representa, na verdade, uma expressäo encobridora e que por isso nos dá a equívoca impressão de plenitude que aparentemente poderia não sofrer rupturas. É precisamente na introdução do nível hermenêutico, que no modo prático de nossa relação com o mundo e de nosso ser-no-mundo, que as rupturas passam a ter sentido, como privação, negação e como falta. É que a totalidade só pode ser simulada no imaginário, e mesmo ao usar esse termo não se quer falar em fantasia, mas no elemento afetivo-emocional do processo pulsional que sustenta o desejo. É ele que erra o objeto e termina a caminho do objeto perdido porque não desiste de uma plenitude impossível.

É a insuportabilidade que nos traz algo de evidente e de ameaçador, quando irrompe nas estruturas de nosso mundo uma modalidade de ser inconclusa, que pode ser levada como uma espécie de outro lado, que nos acompanha na existência ou então como um ponto de virada onde se inicia um novo acontecer. Freud era implacável ao se referir àqueles que apelavam para o recalcamento diante do estranho que fazia sua entrada triunfal na vida ou ao se encontrar com aqueles que pactuavam com o recalcamento onde aparecia justamente a possibilidade de superar o compromisso podre com a existência.

Como era impossivel a eliminação de qualquer nova surpresa por parte do estranho, sendo que este sempre deve ser interpretado como nossa condição de seres sexuados postos no limite pela castração ou pela lei, a expectativa de que a relação que se iria estabelecer entre analisante e analista levaria à cura, era nada mais do que a proposta de um jogo sedutor para ambos os lados: Vamos brincar de doutor?

É por isso que a idéia da inanalisabilidade ou da análise infinita reaparece, em várias passagens, nas obras de Freud. Não terminamos a análise porque a cura representaria uma plenitude, a supressão do objeto perdido e o encontro narcísico das primeiras experiências eróticas em nosso comportamento junto da mãe. É por isso que na análise não há regressão. Todas as situações nos põem diante da nossa incurável condição de ser-no-mundo.

Partimos do modo de ser-no-mundo e da perturbação na relação de objeto até enfrentarmos a tarefa de sua desconstrução a partir do modo finito de ser-nomundo. Falta-nos agora apenas a tarefa de mostrar, num exemplo, como se pode observar uma situação concreta que nos mostra, a partir de um novo regime de objetos, o caráter positivo de nossa desconstrução. Não é o único caminho que podemos seguir na análise das relações entre psicanálise e filosofia, mas certamente, o que foi exposto não permitirá mais um uso ingênuo da expressão relação de objeto. 


\section{3- Culpa e melancolia - um novo regime de objetos ${ }^{4}$}

\section{VIII}

A vontade tende a se isolar como vontade, ela se inclina a arrancar de si mesmo a verdade e a dominá-la com violência. Talvez seja com uma sentença desse tipo que a idéia da finitude do Dasein gostaria de enfrentar as coisas para esconder o seu temor por não ter uma estrutura individual que the garante poder suportar o inelutável de seu destino. É nesse caminho que se desenvolve uma forma de crise diante do mundo; é nele que se produz uma espécie de obscurecimento daquilo que poderia ser o sentido do que realmente se quer. Mas nisso se infiltra algo de impensado que nos traz uma unidade pelo lado avesso do nosso modo de ser. É como se nenhuma habilidade, nenhuma aprendizagem nos pudesse liberar da inquietude, da agitação e da angústia.

Simplesmente somos surpreendidos diante de algo que vai além do nosso querer e que não se enraíza num estado de estabilidade. Não conseguimos organizar esse sentimento com suficiente serenidade, nem seria ele eliminado pela entrega a um fatalismo. Entretanto, é numa emergência da responsabilidade diante da culpa do mundo que a situação é enfrentada. Parece que os instrumentos e a sobranceria com que se poderia conduzir a luta pela existência também não são suficientes para nos libertar dessa inquietude. Ela, no entanto, não faz parte da ordem do mundo, diante da qual fôssemos confessar fraqueza, covardia e comodidade. Tudo é como se tentássemos nos esquivar diante de exigências últimas.

Ao mesmo tempo, em que aparece a tentação de abandonarmos tudo diante do incontrolável, contudo, percebemos um tipo de imperativo de referências mais nobres e de algo inusitado que é sustentado nesta situação que, de um lado, parece dever ser atribuido ao que está fora de nós e que de lá fere o mais suscetivel e o mais vulnerável da vida do ser humano e, de outro lado, aparece como o comportamento mais intimo diante de estados últimos em nós mesmos, que nos põem em constante ameaça e que acenam com a probabilidade do naufrágio, caso não percebamos nisso a presença de uma grandeza inusitada e de uma entrega à ordem do mundo que nós mesmos somos, para daí extrairmos as condições para recuperar o significado e a força da presença das coisas e dos objetos.

Somente uma desconstrução da relação de objeto, pensada a partir da finitude do Dasein é capaz de mostrar-nos a ambigüidade de nosso comportamento diante dos objetos no mundo. Eles, ao mesmo tempo em que parecem ser resultado de uma relação sólida com o mundo, de outro lado, são ao mesmo tempo, diluídos como resultado de sua própria descontinuidade e fragmentação. Não somos senhores do mundo porque somos capazes de nos relacionarmos com objetos mas, somos capazes de nos relacionarmos com objetos porque somos senhores do mundo. Isso não quer dizer, portanto, que sejamos donos do mundo, mas que a

4 Esta parte do ensaio foi apresentada como conferência com o mesmo título no Colóquio Existência e Culpabilidade que se realizou na PUCRS, nos dias 1, 2 e 3 de outubro de 1997, sob a responsabilidade do Centro de Estudos Integrados de Fenomenologia e Hermenêutica do Curso de PósGraduação em Filosofia da mesma universidade. 
articulação do mundo é, ao mesmo tempo, algo que resulta de nossa existência e algo que a determina.

A desconstrução da relação de objeto tem muito a ver com a inserção de sua presença num mundo que nos constitui e que sempre aponta para além da relação de objeto. Nesse sentido, mesmo antes da psicanálise, podemos observar na relação de objeto, a busca do objeto perdido. Isso não se diz simplesmente por amor a uma linguagem hermética. Falar de objeto perdido é reconhecer a dualidade que acima descrevemos: sem a solidez dos objetos no mundo não suportariamos a fragilidade de nosso mundo sem objetos. Poderiamos descrever tudo isso como uma simples objetificação apresentada de modo ambivalente, mas, na verdade, o que descrevemos nesse contexto, é o imperar da experiência da própria finitude do Dasein.

Estamos, assim, situados num novo regime de objetos. Deles não vem a nossa segurança de estar no mundo, mas, sem a experiência da constante possibilidade de perda dos objetos, não seríamos capazes de compreender o que é ser-nomundo. Nesse contexto, se organiza o espaço onde, ao mesmo tempo, em que se supera a exterioridade, se constrói uma intimidade que não vem de dentro. É isso que está na raiz de nossa inquietude e que nos converte em seres habitados pela nostalgia de uma intimidade perdida. Se fôssemos recorrer à terminologia freudiana falariamos da experiência do estranho e do sinistro.

Mas, a partir do que até agora foi dito, a nossa própria condição humana oscila entre a familiaridade e a estranheza. A existência mesma é estranha e familiar. Dizer isso tudo só é possivel porque a desconstrução da relação de objeto nos situou diante da busca do objeto impossivel que experimentamos basicamente sempre como objeto perdido.

Não encontrar morada definitiva entre os objetos descobre em nós a fonte originária, a partir de onde se constitui a possibilidade de contato com a realidade que certamente não é simplesmente de coisas, mas que se complexifica a partir de um mundo que dela emerge. Por isso as coisas não são inteiramente inocentes para nós, elas remetem a um perigo que produz nossa ansiedade, angústia e fragilidade. Mas é um perigo de tal tipo que nos permite recorrer ao poeta: "Onde está o perigo, nasce também a salvação"(Hölderlin).

O novo regime de objetos pode, portanto, ser visto como uma ameaça e uma possibilidade. A resposta definitiva nunca estará apenas de um lado, ela se constitui muito mais a partir da manifestação do próprio modo de ser da existência.

\section{IX}

A desconstrução da relação de objeto, a partir do lidar com o ente disponível, aqui tomado como um dos modos fundamentais do estar-aí que resultam da modificação de sua temporalidade, mostrou-nos que o regime em que se revela nossa ligação com os objetos apresenta uma profunda ambigüidade. Contra a opinião do senso comum de que nossa representação dos objetos e o lidar com eles teriam um sentido univoco e seguro, descobrimos que a relação de objeto remete sempre a algo que se situa num campo mais amplo onde, ao mesmo tempo em que os 
objetos nele se enraízam, dele também recebem uma constante ameaça de perderem segurança e confiabilidade, nos jogarem no desamparo.

É por isso que o exame da duplicidade da relação de objeto que emerge da analítica existencial, deve ser vista como a tentativa de nos assegurar um campo sólido de representações, mostrando-se contudo, que ela é resultado de um trabalho de encobrimento. Certamente, esse trabalho situa-se estruturalmente em nosso próprio modo de ser-no-mundo, mas, ao mesmo tempo, aparece como um fenômeno que perpassa nossa experiência cotidiana. É aí que propriamente surgem as perturbações resultantes da dificuldade em mantermos presente, na relação de objeto, algo que sustente a relação e algo que desfaça o objeto num espaço em que falamos de objeto perdido.

Nossa representação portanto, tem um forte caráter ilusório e aponta para 0 mundo onde os objetos representados são sustentados por um sentido que thes tira o caráter de objeto. Não são os objetos que constituem a solidez de nosso mundo, mas é o mundo que nos mostra os objetos em constante processo de evanescimento. Quando se sustenta a afirmação de que os objetos não possuem a exterioridade imaginada no mundo e não participam de uma intimidade interna, somos levados a reconhecer que nossa existência empírica traz, em seu bojo, uma inconsistência que procuramos encobrir, concentrando-nos no modo de ser-juntodos-entes (no presente). Na experiência empírica esta inconsistência mostra-se não diretamente ligada aos outros dois aspectos da existência que são o futuro e o passado. Esta inconsistência irá aparecer nas vivências do cotidiano como uma espécie de duplo do objeto, como sua sombra, como um estranho que segue de perto a familiaridade. Suportar essa vivência de dilaceramento produziria uma verdadeira paralisia de nosso agir e fazer as coisas. É por isso que realizamos um compromisso fictício conosco, como defesa contra a constante invasão de uma sensação de inutilidade de nosso esforço de consolidar nossa relação de objeto.

A experiência dessa fragmentação não consegue ser totalmente encoberta. Poderíamos falar de um modo de deslizamento que não pára, ou de um vazamento que não pode ser interrompido. Falar em finitude do Dasein enquanto cuidado e temporalidade, pode parecer uma violência para o fenômeno tão essencial que nos acompanha em nossa atividade cotidiana. Entretanto, já vimos em momentos anteriores, que tais filosofemas representam uma espécie de muleta, um constructo para simular todos esses elementos numa unidade.

De fato, esse dilaceramento é vivido em nosso mundo pessoal e no mundo da cultura, jogando-nos muitas vezes, entre o imaginário e o simbólico, não nos eferece lugar seguro. Estamos sempre confrontados com a perda de objeto, mas incessantemente o reconstituímos pagando o preço, de um lado, do mal-estar na cultura e de outro lado, de sujeitos sempre desvanecidos pela falta.

As duas tendências de encontrar uma intimidade na cultura e uma espécie de exterioridade no sujeito, terminam levando-nos sempre, para uma forma de indolência do coração, na qual desesperamos de poder dominar os objetos e nos instalarmos de maneira definitiva na cultura.

Se quisermos focar, pois, o que nos resta como objeto perdido, após a desconstrução do objeto, somos levados a enfrentar a questão da culpa e da melanco- 
lia. De um lado, ficamos devendo a nós mesmos uma realidade sólida, porque estamos sempre remetidos ao estranho. De outro lado, a busca do objeto perdido que nos constitui como experiência na finitude, nos impede de nos desligarmos do objeto, pois não conseguimos substituir a falta, e isso nos conduz para a melancolia.

Não nos iremos deter em análises teóricas da questão da culpa, sobre a qual já temos escutado exposições tão importantes, nem nos iremos aprofundar na questão da melancolia do ponto de vista da analítica existencial. Também dela sabemos o essencial por estudos que nos rodeiam. Nossa intenção é explorar, a partir da visão que obtivemos do novo regime de objetos, pela desconstrução da relação de objeto. Nosso lidar com os entes disponiveis foi analisado com a intenção de prepararmos uma interpretação de um fenômeno de nossa cultura, que nos situa de um outro modo, diante do objeto perdido e seus efeitos sobre a cultura e a existência. Iremos examinar a presença do estranho que se filtra numa tendência quase onipresente na arte contemporânea. Nela são explorados elementos que nos ligam à ruína e à morte dos objetos que nos rodeavam com sentido. Trata-se de diversos tipos de expressões artísticas que exploram os restos, a sucata, o lixo e os elementos descartáveis de nosso cotidiano.

\section{$\mathrm{x}$}

"Se o heimlich é a marca de nosso apego ancestral ao mundo, o signo de uma intimidade antiga e contínua com ele, qual é então, no começo deste século, o acontecimento que parece expulsar a pintura para fora desta habitação, deste lar, desta Heimat, - de que ele possuía a guarda e o prazer, - para esta exterioridade entregue ao silêncio e à solidão, o estranho e 0 inquietante daquilo que ela não reconhece mais, a não ser sob o aspecto da nostalgia de uma intimidade perdida?" (Clair, Jean - Malinconia - Motifs saturniens dans l'art de l'entre-deux-guerres, Gallimard, 1996, p. 75.)

Ao nos depararmos com uma pergunta com as dimensões da que lemos e que se refere ao problema da arte em nosso século, muitas das teses que antecipamos parecem tomar o seu verdadeiro lugar. Há, sem dúvida, nessa pergunta, o clima da melancolia e a sondagem pelo que se pode fazer no limiar de um tempo de grande desolação.

Não se trata de tomar aqui, como objeto de análise, a estética da metafísica que desencadeou a difusão do tema da melancolia (De Chirico). O que nos interessa é a fragilidade do contexto de um mundo ameaçador, em que aparecem os objetos da arte.

Diante da impotência para pensarmos o luto pelo que se experimenta "de perda irremediável de seu objeto", nos perguntamos se é possível restaurar uma cultura através de algum tipo de ação dos indivíduos ou se nos devemos resignar diante da situação singular do ser humano, carregando em si todas as ambigüidades possíveis com o temor inconsolável de uma perda que tal pergunta descreve.

Coisa semelhante vem registrado na experiência de Freud, descrita em Uma perturbação de memória na Acrópole, quando foi atravessado por um sentimento de estranheza e alheiamento. $O$ pensador escreve: "Tudo isso existe realmente 
como nós o temos aprendido na escola?" Diante da ruínas da Acrópole Freud recupera repentinamente toda uma realidade composta de objetos conhecidos e, contudo, perdidos para sempre do seu contexto vivo e original. Essa invasão do estranho é causada pela ambigüidade dos objetos conhecidos e difundidos e as ruínas que mostram o transitório da experiência humana da arte.

Ao visitarmos museus contemporâneos, sobretudo exposições como a Bienal de Veneza ou a Documenta de Kassel, toda a nossa percepção da obra de arte é desconstruida e por mais que tenhamos seguido os mais variados caminhos de iniciação, o desconhecido nos interroga e não sabemos mais quem de fato somos, atingidos pelo estranhamento e pela solidão dos objetos sígnicos cuja função seria provocar nossa participação ou nos paralisar pelo deslumbramento.

Não são apenas as formas e os modos de apresentação que nos confundem mas é, sobretudo, a aterradora distância que se interpôs entre os objetos com que lidamos, no cotidiano, e aqueles que compõem os quadros. Nossa existência é tocada pela distorção do nosso próprio mundo que se mostra estranho e ameaçador pelos objetos familiares perdidos, num contexto em que os perdemos para sempre.

Quando Hegel falava da morte da arte, fazia-o por razões de seu sistema que lhe fornecia uma chave de interpretação e os argumentos para anunciar o seu ocaso. Se hoje, novamente falamos de morte da arte, essencialmente 0 fazemos pela perturbação que ela é capaz de despertar nas nossas relações, aparentemente sólidas, com os objetos, mas que estão irremediavelmente perdidos num mundo que assim não faz sentido.

"A quantidade de sentido é exatamente proporcional à presença da morte $e$ do poder da ruína", diz W. Benjamin em seu Trauerspiel. O que o autor queria dizer é que na medida em que os objetos aparecem deformados e tirados do contexto do nosso lidar com os entes disponiveis estamos colocados diante de duas hipóteses - a) ou o estranho invade nossa experiência com a nostalgia do objeto perdido; b) ou na medida em que a história é fetichizada, sob a forma de objetos que faziam parte de nosso mundo, mas que agora aparecem reduzidos a objetos materiais, a história pode ser compreendida em seu enigma, porque paralisada.

Em sua Filosofia da história, Benjamin sugere opor a essa aparente compreensão da históna, um outro método que nos possa revelar as verdadeiras dimensões da perda. "É o método da intropatia. Ella nasce da indolência do coração, da acedia que desespera de poder dominar a verdadeira imagem do que acontece, aquela que brilha de maneira fugidia." A acedia é a fonte da tristeza entre os medievais. Nós a conhecemos como melancolia. O que está atrás desse sentimento é a culpa de que ficamos devendo algo radical com relação aos objetos. Eles não se apresentam apenas como objetos perdidos. Eles revelam assustadoramente a nossa própria condição humana incapaz de levar ao fim o luto pelo objeto perdido. Ela se paralisa diante da eterna repetição de uma perda que jamais se consuma.

\section{XI}

Quando nos postamos diante de uma obra de arte para contemplá-la, não nos despimos das estruturas fundamentais que nos determinam como seres no mundo. 
É nesse sentido que a obra de arte nos atinge nos modos fundamentais de nosso ser. Nós não olhamos um quadro com a inocência de quem nunca presentificou os objetos com que lida. Também a obra de arte é um ente disponível, ainda que gostaríamos de nela descobrir outros aspectos de nossa existência. É por isso que não podemos evitar de transformar um quadro de um autor determinado, em objeto.

No entanto, ao transformá-lo em objeto, nós simplificamos o modo como efetivamente o quadro nos atinge. Ocultamos, de certa maneira, dimensões que talvez até estejamos procurando na obra de arte, mas que nos perturbariam demasiadamente se não a víssemos apenas como um objeto no presente. Qualquer obra de arte é perturbadora quando nela aparecem, no encontro conosco, o futuro e o passado: a existência e a faticidade. As modificações da temporalidade que revelam modos de sermos no mundo, também nos modificam no momento em que estamos diante de uma obra de arte. Basicamente essa modificação representa uma invasão da totalidade em nosso estar distraídos diante de um objeto presente. O ser-adiante-de-nós-mesmo, e o já-ser-em, inelutavelmente, colocam-nos diante da finitude e da historicidade, diante do não-ser-mais e do já-sempre-ser sem volta. Essas formas de manifestação da temporalidade perturbam o modo como estamos decaídos, perdidos no lidar com os entes como objetos no presente.

Esta é a razão porque também diante de uma pintura, estamos em constante fuga de nós mesmos. A arte clássica conseguia dar-nos, de maneira muito sutil, uma impressão de familiaridade. É por isso que a manobra de encobrimento diante do estranho, que também delas nos surpreendia, se fazia de maneira menos angustiante. Diante de uma obra contemporânea, sobretudo, quando usa para sua composição objetos de nosso cotidiano tomados da sucata, do lixo e do descartado, surge um estranhamento do qual dificilmente conseguimos nos esconder. Os próprios objetos do nosso cotidiano aparecem ai deformados, alienados de nosso uso e perdidos para sempre, num novo contexto. A ruína e a morte passam a constituir um sentido que nos revela não apenas algo fugaz, mas nos desmascara na vontade de fugir para a ocupação com os entes simplesmente presentes, para esquecermos o estranho e o ameaçador que vem do futuro e do passado.

É por isso que a visita a um museu de arte contemporânea nos põe, de maneira muito forte, diante do irrecusável destino: Com os objetos perdidos de nossa proximidade para sempre, a culpa e a melancolia emergem diante de um mundo que está por deśaparecer e com o qual desapareceremos. A euforia da arte sinistra que nos quer chocar é um breve e transitório apelo para nos avisar: a arte hoje é uma sofisticada e generosa ilusão. Ao menos assim nos atingem as experiências que se fazem com muitas formas de arte contemporânea.

Os objetos perdidos e que, por isso, deixam de ser objetos de nosso lidar no cotidiano, nos remetem para a distância em que estamos de nós mesmos. Assim, a arte hoje é a grande forma da melancolia. Isto é, um trabalho de luto que não chega ao fim e assim se converte no movimento infinito da melancolia.

Walter Benjamin fala, no fim de suas Teses sobre a filosofia da história, dando a essa melancolia um sentido histórico e político: "A natureza dessa tristeza tornase mais evidente quando nos perguntamos com o que propriamente o historiógrafo 
historicista entra em intropatia. A resposta é inelutável: com o vencedor." E, Benjamin, continua: "Ora quem quer que domine é sempre o herdeiro de todos os vencedores. Entrar em intropatia com o vencedor beneficia sempre, por conseguinte, àquele que domina. Não há nenhum documento de cultura que não seja, também, um documento da barbárie."

Diante dos fragmentos de nossos objetos familiares, diante do lixo, da sucata e da ruina que compõem grande parte das artes plásticas hoje, descobrimos a ambigüidade da arte. Ela, ao mesmo tempo, em que protesta contra a transitoriedade, alia-se a ela e utiliza a sua matéria para produzir nas obras atuais, simultaneamente, um documento de uma barbárie que quer ser também o documento de uma cultura.

Parafraseando Freud diante das ruínas da Acrópole, somos tentados a perguntar: Tudo isso existiu realmente no mundo dos objetos com que lidamos no cotidiano? Tal interrogação mostra a estranheza que nos ameaça na obra de arte e que nos põe, sem máscaras, diante de nossa finitude que sempre estamos empreendendo disfarçar com a segurança de nossos objetos no presente.

É claro que nem toda a obra de arte nos joga tão diretamente contra os nossos limites. Mas isso não é um defeito ou uma doença da obra. Mais que outras, talvez ela nos traga um grande número de sinais que indicam que a solidez $e$ as regras com que nos construímos como sujeitos nos traíram e nos revelaram, porque "mudaram" nossos objetos, abrindo assim uma fresta para que aparecesse a nossa verdade. 